\title{
Erratum to: Pigmented villonodular synovitis of the shoulder associated with massive rotator cuff tear treated by arthroscopic synovectomy and debridement
}

\author{
S. Gumina $\cdot$ S. Carbone $\cdot$ V. Campagna $\cdot$ \\ A. Castagna $\cdot$ C. Della Rocca $\cdot$ G. Giannicola
}

Published online: 21 May 2013

(C) Istituto Ortopedico Rizzoli 2013

Erratum to: Musculoskelet Surg (2013) 97 (Suppl 1):

S79-S84

DOI 10.1007/s12306-013-0258-Z

In the original article, one of the co-author's (C. Della Rocca) family name has been published incorrectly. The correct family name should be Della Rocca.

The online version of the original article can be found under doi:10.1007/s12306-013-0258-z.

S. Gumina $(\varangle) \cdot$ S. Carbone $\cdot$ G. Giannicola Department of Orthopaedic and Traumatology, University of Rome Sapienza, Rome, Italy

e-mail: stefcarbone@yahoo.it

V. Campagna

Department of Orthopaedic and Traumatology,

Policlinico Militare Celio, Rome, Italy

\section{A. Castagna}

Department of Orthopaedic and Traumatology,

Istututo Clinico Humanitas, Milan, Italy

C. Della Rocca

Department of Medical-Surgical Science and Biotechnologies,

University of Rome "Sapienza", Rome, Italy 